Gozgor, G., Demir, E. (2018). The Effects of Economic Policy Uncertainty on Outbound Travel

Expenditures. Journal of Competitiveness, 10(3), 5-15. https://doi.org/10.7441/joc.2018.03.01

\title{
THE EFFECTS OF ECONOMIC POLICY UNCERTAINTY ON OUTBOUND TRAVEL EXPENDITURES
}

- Giray Gozgor, Ender Demir

\begin{abstract}
Tourism has been one of the fastest growing industries and it makes important contributions on economies. Based on this, the literature aims to determine the factors affecting tourism demand behavior. In this paper, we analyze the effect of economic policy uncertainty (EPU) on both total and personal outbound travel expenditures in the panel data of 17 developed and developing countries. This is the first paper to examine the impact of EPU on travel expenditures within a tourism demand framework. By using the fixed-effects and the Least Square Dummy Variable (LSDV) estimation techniques, we find that an increase in the level of uncertainty decreases travel expenditures. Our findings imply that when people experience an increase in uncertaintyrelated economic policies, they tend to decrease their expenditures abroad. On average, a one standard deviation rise in EPU leads to a 3\% and a $6 \%$ decrease in the total and personal travel expenditures. We also find that the effect of EPU on travel expenditures is higher in developing economies compared to developed countries. The empirical results in this paper suggest that governments should realize the suppressing effect of uncertainties about their economic policies on tourism demand.
\end{abstract}

Keywords: travel expenditures, outbound tourism, economic policy uncertainty, panel data estimation techniques, tourism competitiveness

JEL Classification: Z32, Z39, Z30

Received: May, 2018

1st Revision: July, 2018

Accepted: August, 2018

\section{INTRODUCTION}

Tourism has been continuously expanding over the past six decades. Over the last decade, China has been the rising star in global tourism expenditures. Indeed, China plays a leading role in global outbound travel in terms of tourism expenditures for the period from 2004 to 2015. The market share of China is $23.2 \%$ ( $\$ 292.2$ billion) in international tourism expenditures, followed by the United States ( $9 \%$ market share) and Germany (6.2\% market share). Among the top 10 countries in international tourism expenditures, Germany, France, Russia, Canada, Italy, and Australia experienced a decline in 2015 compared to 2014. However, tourism expenditures in the United States increased from US\$ 105.5 billion in 2014 to 113 billion in 2015. Plus, outbound 
tourists in the United States reached 73.5 million (United Nations World Tourism Organization (UNWTO), 2016).

Based on the importance of tourism and its contributions, it is important to determine the factors affecting tourism demand behavior (Dragouni et al., 2016). Possible determinants of outbound tourism expenditures are analyzed both within a macro framework as well as micro framework. Macro-based studies use macroeconomic time series data in order to construct aggregate expenditure models of international tourism expenditures. By using surveys, micro-based studies try to examine "why", "how" and "on what" the tourists spend their money (Sheldon, 1990). While the exchange rate, income, and prices are the main determinants used by macro-based studies (Uysal \& El Roubi, 1999), micro-based studies use a large set of variables, such as age, gender, income, length of stay, marital status, occupation, purpose of the trip, and travel party size (Sainaghi, 2012).

While there is a rich literature on micro-based studies, the number of macro-based studies are relatively scarce. For example, Davila et al. (1999) focus on the impacts of lowered duty-free import limits on the outbound tourist expenditures in the case of Mexican cross-border visitors from the United States. Contrary to the expectations, a policy like establishing import limits might fail to decrease expenditures on U.S. goods by Mexican cross-border tourists. Moreover, the overall expenditures in the United States, which come from the Mexican cross-border tourists, will likely increase. Vietze (2011) shows that economic factors (such as the gross domestic product per capita and trade openness), institutional quality (such as civil rights, political stability, effective governance, the level of corruption and freedom to speak), sociological factors (such as literacy rate and life expectancy), and tourism information affect outbound tourism expenditures. Using a panel data from 80 countries over the period 1999-2011 and applying both the fixed-effects and the generalized methods of moments (GMM) estimation techniques, Gholipour et al. (2014) examine the impact of personal freedom on outbound tourism, and it is measured by both the number of outbound travelers and international tourism expenditures. They show that both outbound tourism proxies are negatively associated with personal freedom. Moreover, disposable income, exchange rate, and travel costs also affect outbound tourism expenditures. Using the data from 49 countries over the period 2006-2011, Gholipour and Tajaddini (2014) explore the relationship between Hofstede's cultural dimensions and the expenditures of tourists. They find that Hofstede's cultural dimensions for individualism / collectivism, indulgence / restraint, pragmatism / normative, and uncertainty avoidance affect the spending behavior of tourists.

In this paper, we focus on the effect of Economic Policy Uncertainty (EPU), which is developed by Baker et al. (2016) on outbound travel (tourism) expenditures using the panel data of 17 countries. The regressions also introduced relevant control variables. Previous findings imply that the EPU can affect consumer spending behavior (Baker et al., 2016; Dragouni et al., 2016; Giavazzi \& McMahon, 2012). For example, Giavazzi \& McMahon (2012) show that households in Germany increase their savings (which means a decrease in spending) when economic policy uncertainty increases.

Indeed, increases in economic policy uncertainty make businesses postpone their investments and households postpone and/or decrease consumption expenditures. Increasing uncertainty 
will make people reluctant to spend more for holidays abroad. There is a growing literature on tourism demand; however, outbound tourism (especially outbound tourism expenditures) remains relatively under-researched (Seetaram, 2012). While Demir \& Gozgor (2018) analyze the impact of EPU on outbound tourism, this study focuses on the effect of EPU on outbound tourism expenditures. Our measure in the paper is the seminal uncertainty measure of Baker et al. (2016), known as EPU. We found out that there is a negative impact of economic policy uncertainty on the total outbound and personal outbound travel expenditures in the panel dataset of 17 economies. Our findings imply that when people experience an increase in uncertainty-related economic policies, they tend to decrease their expenditures abroad. According to the findings, the negative effect of EPU on travel expenditures is also higher in developing economies than in developed ones.

The rest of the paper proceeds as follows: Section 2 briefly explains EPU and presents the previous literature on the effects of EPU on tourism indicators. Section 3 describes the data and econometric methodology. Section 4 presents the empirical findings and discusses the implications. Section 5 concludes the paper.

\section{PREVIOUS LITERATURE ON THE EFFECTS OF EPU ON TOURISM}

We use the EPU index, which is constructed by Baker et al. (2016). For details on the EPU index, visit http://www.policyuncertainty.com/. The existing literature investigates the effects of EPU on the firm-level decisions, gold prices, macroeconomic variables, oil prices, and stock markets. Recently, the EPU is also being used as a proxy for its potential effects on the tourism sector. For example, Dragouni et al. (2016) investigate the spillover effects of sentiment and mood shocks on the U.S. outbound tourism demand. It is shown that there is a significant interrelationship among sentiment, mood, and outbound tourism demand in the U.S. Demir \& Gozgor (2016) document that the EPU causes a decrease in the vehicle miles traveled (VMT) in the U.S. for the time period of 1978-2014. Chatziantoniou et al. (2016) document that a higher level of the consumer confidence index is positively related to a higher demand for the outbound tourism. Specifically, the consumer confidence in Canada and the United Kingdom (UK) will be an important predictor for future arrivals from the related countries to Greece. Likewise, the price level is important for France and Germany, the income level is important for Italy and Spain, and the EPU is important for the tourist arrivals from the U.S. to Greece. On the other hand, Demir \& Ersan (2018) show that the EPU in Europe and Turkey both have significant and negative effects on the stock returns of the listed tourism companies in Turkey over the period 2002-2013. Gozgor \& Ongan (2017) focus on the potential effects of the EPU on domestic tourist spending in the U.S. They find that a higher level of the EPU leads to the significant declines in tourism spending of the U.S. domestic tourists in the long run. Within a tourism demand framework, Demir \& Gozgor (2018) examine how the EPU affects the outbound tourism. Using the panel data of 15 countries, they find that a higher level of the EPU leads to a decrease in the outbound tourism. 


\section{DATA, EMPIRICAL MODEL, AND ECONOMETRIC METHODOLOGY}

\subsection{Data and Empirical Model}

The EPU indexes, which are developed by Baker et al. (2016), are available for 17 countries in 2017 (see appendix 1). Beginning periods of the EPU indexes are different for each country and this leads to the unbalanced panel dataset in the empirical examination. The selection of countries in the empirical analysis depends on the data availability. The empirical analysis begins in 1995 and ends in 2015 and this is related to the data availability of tourism expenditures. Since the tourism flows are defined in the annual frequency, the empirical analysis uses the data in the annual frequency.

The dependent outbound tourism variables are the total outbound travel expenditures and personal outbound travel expenditures by the amount of travel expenditures (in the USD) from their country to any other country. The data are obtained from the database of the United Nations World Tourism Organization. The control variables are obtained from the World Development Indicators database of the World Bank. Estimation model and the control variables are based on Gholipour \& Tajaddini (2014) and Gholipour et al. (2014). The empirical models can be defined as follows:

$$
\begin{aligned}
& \text { TRAVEL_EXP } P_{i t}=\beta_{0}+\beta_{1} E P U_{i t}+\beta_{2} \text { POPULATION }{ }_{i t}+\beta_{3} I N F L A T I O N+\beta_{4} E X C_{i t}+\beta_{5} \\
& G_{i t}+e_{i t}
\end{aligned}
$$

$$
\begin{aligned}
& \text { PER_TRAVEL_EXP } P_{i t}=\beta_{0}+\beta_{1} E P U_{i t}+\beta_{2} \text { POPULATION }{ }_{i t}+\beta_{3} I_{\text {INFLATION }+\beta_{4}} \\
& \mathrm{EXC}_{i t}+\beta_{5} G_{i t}+e_{i t}
\end{aligned}
$$

where, $i=1, \ldots, \mathrm{N}$ denotes the country; $t=1, \ldots ., \mathrm{T}$ denotes the time period. TRAVEL_EXP ${ }_{i t}$ and PER_TRAVEL_EXP ${ }_{i t}$ are the dependent variables, which indicate the natural logarithm of total outbound travel expenditures and personal travel expenditures from country $i$ at time t, respectively. GDP it is the GDP and, POPULATION $N_{i t}$ is the population of country i. EXC $C_{i t}$ is the domestic currency unit/US Dollar, and INFLATION ${ }_{i t}$ is the change in the consumer price index (CPI). In addition, EPU $U_{i t}$ is measured as the natural logarithm of the economic policy uncertainty index.

\subsection{Econometric Methodology}

We estimate the empirical models in Eq. (1) and Eq. (2) by using the fixed-effects and the Least Square Dummy Variable (LSDV) estimation technique of Bruno (2005a and 2005b). Previous empirical papers usually consider the GMM estimation technique; however, it can provide inconsistent results in the panel data with a small number of countries (Bruno, 2005b). Indeed, this is the case in the data set of our empirical examination. In the LSDV estimations, we realized that tourists going to foreign countries prefer to go to the same country in the future, known as the "persistence effect". The number of observations in the data set is 315 and the data are based on 17 countries. The issue of a small number of countries is particularly important for separate empirical examinations for 11 developed and 6 developing countries. In short, it would be better 
to perform the LSDV estimations, instead of the GMM, to overcome potential problems in the small number of cross-section in the panel data sets.

\section{RESULTS AND DISCUSSION}

We report the results of the regression estimations in Table 1, 2, and 3 for the full sample, developed countries and developing countries, respectively. The coefficient of the EPU for the fixed-effect estimations is -0.04 in Column 1 and this indicates that a rise in the EPU leads to a decline in the travel expenditures. In addition, the results of the Hausman test indicate that the fixed-effects estimations in Columns (1), (3), (5), (7), (9), and (11) of Table 1, 2, and 3 are efficient. All coefficients for the lagged total outbound travel expenditures and the lagged personal travel outbound expenditures are also statistically significant at the $1 \%$ level.

In Column 2, we report the results of the LSDV estimation. In all LSDV estimations, the bias correction is initialized by the Blundell-Bond estimations. In addition, the period fixed-effects are considered. The coefficient of the EPU in Column 2 is -0.066 and it is statistically significant at the $1 \%$ level. This result states that the findings of the negative effects of the EPU on the travel expenditures are robust to different econometric methods. More specifically, a $10 \%$ rise in the economic policy uncertainty index reduces $0.66 \%$ in the total outbound travel expenditures. In other words, a one standard deviation rise in the economic policy uncertainty index (45.6 point rise), leads to a $3 \%$ reduction in travel expenditures.

Furthermore, the coefficient of the EPU for the fixed-effect estimations is -0.08 in Column 3 and this result shows that a higher level EPU leads to a decline in the personal outbound travel expenditures. According to the results of the LSDV estimations in Column 4, the coefficient of the EPU in Column 2 is -0.133 and it is statistically significant at the $1 \%$ level. This result indicates that the findings of the negative effects of the EPU on the personal outbound travel expenditures are robust to different econometric methods. More specifically, a $1 \%$ rise in the economic policy uncertainty index leads to a reduction of $0.133 \%$ in the personal outbound travel expenditures. In other words, a one standard deviation rise in the economic policy uncertainty index (45.6 point increase) leads to a $6 \%$ reduction on the personal travel expenditures. Following these results, we suggest that the EPU index can be seen as a significant limitation of tourism development. Indeed, people seek to reduce or postpone their travel expenditures to other countries in the times of higher economic policy uncertainty.

Tab. 1 - Results of the Fixed-Effects and the LSDVC Estimations. Source: authors

\begin{tabular}{|l|l|l|l|l|}
\hline \multirow{2}{*}{ Sample Methodology } & \multicolumn{4}{l|}{ Full Sample } \\
\cline { 2 - 6 } & FE & LSDVC & FE & LSDVC \\
& $(1)$ & $(2)$ & $(3)$ & $(4)$ \\
\hline \multirow{2}{*}{ Lagged log travel expenditures } & $0.774^{* * *}$ & $1.045^{* * *}$ & - & - \\
\cline { 2 - 6 } & $(0.05)$ & $(0.02)$ & & \\
\hline \multirow{2}{*}{ Log economic policy uncertainty } & $-0.041^{*}$ & $-0.066^{* * *}$ & $-0.080^{* *}$ & $-0.133^{* * *}$ \\
\cline { 2 - 6 } & $(0.02)$ & $(0.03)$ & $(0.03)$ & $(0.03)$ \\
\hline
\end{tabular}




\begin{tabular}{|l|l|l|l|l|}
\hline \multirow{2}{*}{ Log population } & $0.577^{*}$ & -0.154 & 0.486 & -0.093 \\
\cline { 2 - 5 } & $(0.33)$ & $(0.20)$ & $(0.42)$ & $(0.30)$ \\
\hline \multirow{2}{*}{ Inflation rate } & $-0.004^{* * *}$ & $-0.005^{* * *}$ & -0.012 & -0.011 \\
\cline { 2 - 5 } & $(0.00)$ & $(0.00)$ & $(0.01)$ & $(0.01)$ \\
\hline \multirow{2}{*}{ Exchange rate } & $-0.001^{* * *}$ & $-0.001^{* * *}$ & $-0.001^{* * *}$ & $-0.001^{* * *}$ \\
\cline { 2 - 5 } & $(0.00)$ & $(0.00)$ & $(0.00)$ & $(0.00)$ \\
\hline \multirow{2}{*}{ Log GDP } & $0.515^{* * *}$ & 0.055 & $0.515^{* *}$ & 0.088 \\
\cline { 2 - 5 } & $(0.08)$ & $(0.08)$ & $(0.20)$ & $(0.16)$ \\
\hline \multirow{2}{*}{ Lagged log personal travel expenditures } & - & - & $0.791 * * *$ & $1.095^{* * *}$ \\
\cline { 2 - 5 } & & & $(0.04)$ & $(0.03)$ \\
\hline \multirow{2}{*}{ Constant term } & $-12.929 * *$ & - & -11.390 & - \\
\cline { 2 - 5 } & $(5.97)$ & & $(6.89)$ & \\
\hline Number of Observations & 315 & 315 & 209 & 209 \\
\hline Number of Countries & 17 & 17 & 17 & 17 \\
\hline Hausman Test & $62.1[0.00]$ & - & $34.8[0.00]$ & - \\
\hline R-Squared & 0.94 & - & 0.89 & - \\
\hline
\end{tabular}

Notes: $* * *, * *$ and $*$ indicate the statistical significance at the $1 \%, 5 \%$, and $10 \%$ levels, respectively. Standard errors are presented in the parenthesis.

In addition, we divide the full sample into 11 developed countries (Australia, Canada, France, Germany, Ireland, Italy, Japan, the Netherlands, Spain, the United Kingdom, and the United States) and 6 developing economies (Brazil, Chile, China, India, Russia, and South Korea). According to the results in Columns (5) and (6) in Table 2, which indicates the effect of EPU on total outbound travel expenditures in the developed countries, the coefficients of EPU are -0.044 for the fixed-effects and -0.073 for the LSDV estimations (both of them are statistically significant at the $1 \%$ level), respectively. According to the results in Columns ( 9 ) and (10), which state the impact of EPU on the total outbound travel expenditures in the developing countries, the coefficients of EPU are -0.056 for the fixed-effects and -0.16 for the LSDV estimations, respectively.

On the other hand, according to the results in Columns (7) and (8) of Table 2, which show the impact of EPU on personal outbound travel expenditures in the developed countries, the coefficients of EPU are -0.048 for the fixed-effects and -0.133 for the LSDV estimations (both of them are statistically significant at the $1 \%$ level), respectively. According to the results in Columns (11) and (12), which show the effect of EPU on the personal outbound travel expenditures in the developing countries (Table 3), the coefficients of EPU are -0.156 for the fixed-effects and -0.242 for the LSDV estimations, respectively. In short, the impact of the EPU index on outbound travel expenditures is higher in the developing countries than the developed ones. 
Tab. 2 - Results of the Fixed-Effects and the LSDVC Estimations for Developed Countries. Source: authors

\begin{tabular}{|c|c|c|c|c|}
\hline \multirow{2}{*}{ Sample Methodology } & \multicolumn{4}{|c|}{ Developed Countries } \\
\hline & $\begin{array}{l}\text { FE } \\
(5)\end{array}$ & $\begin{array}{l}\text { LSDVC } \\
(6)\end{array}$ & $\begin{array}{l}\mathrm{FE} \\
(7)\end{array}$ & $\begin{array}{l}\text { LSDVC } \\
(8)\end{array}$ \\
\hline \multirow{2}{*}{ Lagged log travel expenditures } & $0.878^{* * *}$ & $1.238^{* * *}$ & - & - \\
\hline & $(0.04)$ & $(0.01)$ & & \\
\hline \multirow{2}{*}{ Log economic policy uncertainty } & $-0.044 * * *$ & $-0.073 * * *$ & $-0.048^{* * *}$ & $-0.133 * * *$ \\
\hline & $(0.01)$ & $(0.02)$ & $(0.01)$ & $(0.03)$ \\
\hline \multirow{2}{*}{ Log population } & $0.331^{*}$ & $-1.448^{* * *}$ & -0.233 & -0.093 \\
\hline & $(0.15)$ & $(0.35)$ & $(0.43)$ & $(0.30)$ \\
\hline \multirow{2}{*}{ Inflation rate } & $0.028 * * *$ & $0.028 * * *$ & $0.024 *$ & $-0.010^{*}$ \\
\hline & $(0.01)$ & $(0.01)$ & $(0.01)$ & $(0.01)$ \\
\hline \multirow{2}{*}{ Exchange rate } & $-0.002^{* * *}$ & $-0.006^{* * *}$ & $-0.004 * * *$ & $-0.001 * * *$ \\
\hline & $(0.00)$ & $(0.00)$ & $(0.00)$ & $(0.00)$ \\
\hline \multirow{2}{*}{ Log GDP } & 0.249 & 0.120 & 0.312 & 0.088 \\
\hline & $(0.17)$ & $(0.15)$ & $(0.28)$ & $(0.16)$ \\
\hline \multirow{2}{*}{$\begin{array}{l}\text { Lagged log personal travel expendi- } \\
\text { tures }\end{array}$} & - & - & $0.941 * * *$ & $1.095^{* * *}$ \\
\hline & & & $(0.05)$ & $(0.03)$ \\
\hline \multirow{2}{*}{ Constant term } & $-7.037^{*}$ & - & 1.671 & - \\
\hline & $(3.28)$ & & $(6.34)$ & \\
\hline Number of Observations & 203 & 203 & 133 & 133 \\
\hline Number of Countries & 11 & 11 & 11 & 11 \\
\hline Hausman Test & $30.2[0.00]$ & - & $16.1[0.00]$ & - \\
\hline R-Squared & 0.92 & - & 0.92 & - \\
\hline
\end{tabular}

Notes: $* * *, * *$ and $*$ indicate the statistical significance at the $1 \%, 5 \%$, and $10 \%$ levels, respectively. Standard errors are presented in the parenthesis.

The results indicate that the controls are similar to the previous papers. GDP has a positive effect on travel expenditure, implying that a higher income in a country increases travel demand. The impact of exchange rate is negative, implying that a depreciation of the domestic currency decreases travel expenditures. This finding indicates that people are sensitive to the fluctuations in the value of exchange rates; thus, their travel plans can be significantly affected by the value of the exchange rate. These results are in line with Gholipour et al. (2014). However, the coefficients for the population and the inflation rate (based on the change in CPI) demonstrate mixed effects on travel expenditures. 
Tab. 3 - Results of Fixed-Effects and LSDVC Estimations for Developing Countries. Source: authors

\begin{tabular}{|c|c|c|c|c|}
\hline \multirow[b]{2}{*}{ Sample Methodology } & \multicolumn{4}{|c|}{ Developing Countries } \\
\hline & $\begin{array}{l}\text { FE } \\
\text { (9) }\end{array}$ & $\begin{array}{l}\text { LSDVC } \\
(10)\end{array}$ & $\begin{array}{l}\text { FE } \\
(11) \\
\end{array}$ & $\begin{array}{l}\text { LSDVC } \\
(12)\end{array}$ \\
\hline \multirow{2}{*}{ Lagged log travel expenditures } & $0.734 * * *$ & $1.293 * * *$ & - & - \\
\hline & $(0.09)$ & $(0.00)$ & & \\
\hline \multirow{2}{*}{ Log economic policy uncertainty } & $-0.056^{*}$ & $-0.159 * *$ & $-0.156^{*}$ & $-0.242^{* * *}$ \\
\hline & $(0.03)$ & $(0.06)$ & $(0.08)$ & $(0.05)$ \\
\hline \multirow{2}{*}{ Log population } & $1.036^{*}$ & -0.257 & 0.881 & -0.195 \\
\hline & $(0.51)$ & $(0.63)$ & $(0.45)$ & $(0.30)$ \\
\hline \multirow{2}{*}{ Inflation rate } & $-0.006 * *$ & $-0.011 * * *$ & $-0.022^{* *}$ & -0.010 \\
\hline & $(0.00)$ & $(0.00)$ & $(0.01)$ & $(0.01)$ \\
\hline \multirow{2}{*}{ Exchange rate } & $-0.001 * *$ & $-0.001 * *$ & $-0.001 * *$ & $-0.001 * * *$ \\
\hline & $(0.00)$ & $(0.00)$ & $(0.00)$ & $(0.00)$ \\
\hline \multirow{2}{*}{ Log GDP } & $0.549 * *$ & $0.499 * * *$ & $0.595^{* *}$ & 0.244 \\
\hline & $(0.16)$ & $(0.14)$ & $(0.21)$ & $(0.19)$ \\
\hline \multirow{2}{*}{ Lagged log personal travel expenditures } & - & - & $0.743 * * *$ & $0.951 * * *$ \\
\hline & & & $(0.05)$ & $(0.04)$ \\
\hline \multirow{2}{*}{ Constant term } & $-20.714 *$ & - & $-18.221^{*}$ & - \\
\hline & $(8.99)$ & & $(8.37)$ & \\
\hline Number of Observations & 112 & 112 & 76 & 76 \\
\hline Number of Countries & 6 & 6 & 6 & 6 \\
\hline Hausman Test & $26.4[0.00]$ & - & $15.9[0.00]$ & - \\
\hline R-Squared & 0.95 & - & 0.89 & - \\
\hline
\end{tabular}

Notes: $* * *, * *$ and $*$ indicate the statistical significance at the $1 \%, 5 \%$, and $10 \%$ levels, respectively. Standard errors are presented in the parenthesis.

In short, the empirical results indicate that uncertainty due to economic policies is negatively related to outbound travel (tourism) expenditures. Therefore, policymakers can target a reduction in the level of uncertainty in order to spur outbound tourism expenditures in the related countries in our dataset. Indeed, the empirical results in this paper suggest that governments should realize the suppressing effect of uncertainties about their economic policies on tourism demand. This can be a more noteworthy issue for the policymakers in the developing economies than the policymakers in the developed countries. Governments should avoid frequent changes in the economic policies they are implementing, as frequent changes are likely to cause uncertainty. In case of a policy change or if policy changes are needed, governments should react quickly and take the necessary actions. A further delay or a longer decision period will increase the uncertainty. 
The main finding of our paper is somewhat in line with the previous results of Dragouni et al. (2016), showing that there is a significant spillover from EPU to outbound tourism. The findings of our paper are also in line with the previous findings of Gozgor and Ongan (2017) and Demir \& Gozgor (2016), in which they find that the EPU index is negatively associated with domestic tourism and travel demand in the United States, respectively. Considering the findings of this study along with the previous studies, we conclude that uncertainty is an obstacle in the development of tourism. Countries which can manage to decrease uncertainty can gain a competitive advantage against others. This is even more vital for developing economies, where tourism has a significant role in the economy.

\section{CONCLUSION}

In this paper, we examined the effects of the EPU index on outbound travel expenditures. While the previous literature has considered the effects of various indicators on tourism indicators, the effects of uncertainty measures were neglected. For this purpose, our paper is the first to examine the direct impact of EPU on both total and personal travel expenditures within a tourism demand framework. We focused on the panel data of 17 countries and found that an increase in uncertainty decreases travel expenditures. On average, a one standard deviation rise in EPU leads to a $3 \%$ and a $6 \%$ decrease in total outbound and personal outbound travel expenditures. The negative effect of EPU on travel expenditures is also higher in developing countries than in developed ones.

For future research, it may be useful to examine the direct effects of EPU on tourism market indicators in developed and developing countries with a time-series analysis in order to understand the heterogeneity among countries. For example, France, Italy, and Spain are the most-visited countries in the world, and especially, it would be better to understand the impact of economic policy uncertainty on the travel demand and the development of tourism in these countries. Moreover, future studies can analyze how economic policy uncertainty affects the tourism competitiveness of countries.

\section{References}

1. Baker, S. R., Bloom, N., \& Davis, S. J. (2016). Measuring Economic Policy Uncertainty. Quarterly Journal of Economics, 131 (4), 1593-1636. http://dx.doi.org/10.1093/qje/qjw024

2. Bruno, G. (2005a). Approximating the Bias of LSDV Estimator for Dynamic Unbalanced Panel Data Models. Economics Letters, 87 (3), 361-366. http://dx.doi.org/10.1016/ j.econlet.2005.01.005

3. Bruno, G. (2005b). Estimation and Inference in Dynamic Unbalanced Panel Data Models with a Small Number of Individuals. Stata Journal, 5 (4), 473-500.

4. Chatziantoniou, I., Degiannakis, S., Eeckels, B., \& Filis, G. (2016). Forecasting Tourist Arrivals Using Origin Country Macroeconomics. Applied Economics, 48 (27), 2571-2585. http://dx.doi.org/10.1080/00036846.2015.1125434

5. Davila, V.R., Asgary, N., de Los Santos, G., \& Vincent, V. (1999). The Effects of Governmental Restrictions on Outbound Tourist Expenditures. Journal of Travel Research, 37 (3), 285-290. 
http://dx.doi.org/10.1177/004728759903700310

6. Demir, E., \& Ersan, O. (2018). The Impact of Economic Policy Uncertainty on Stock Returns of Turkish Tourism Companies. Current Issues in Tourism, 21 (8), 847-855. http:// dx.doi.org/10.1080/13683500.2016.1217195

7. Demir, E., \& Gozgor, G. (2016). The Impact of Economic Policy Uncertainty on the Vehicle Miles Traveled (VMT) in the U.S. Eurasian Journal of Business and Management, 4 (3), 39-48. https://doi.org/10.15604/ejbm.2016.04.03.004

8. Demir, E., \& Gozgor, G. (2018). Does Economic Policy Uncertainty Affect Tourism? Annals of Tourism Research, 69 (1), 15-17. https://doi.org/10.1016/j.annals.2017.12.005

9. Dragouni, M., Filis, G., Gavriilidis, K., \& Santamaria, S. (2016). Sentiment, Mood and Outbound Tourism Demand. Annals of Tourism Research, 60 (1), 80-96. http://dx.doi. $\operatorname{org} / 10.1016 /$ j.annals.2016.06.004

10. Gholipour, H. F., \& Tajaddini, R. (2014). Cultural Dimensions and Outbound Tourism. Annals of Tourism Research, 49 (1), 203-205. http://dx.doi.org/10.1016/j.annals.2014.08.006

11. Gholipour, H. F., Tajaddini, R., \& Al-Mulali, U. (2014). Does Personal Freedom Influence Outbound Tourism? Tourism Management, 41 (1), 19-25. https://doi.org/10.1016/ j.tourman.2013.08.010

12. Giavazzi, F., \& McMahon, M. (2012). Policy Uncertainty and Household Savings. Review of Economics and Statistics, 94 (2), 517-531. https://doi.org/10.1162/REST_a_00158

13. Gozgor, G., \& Ongan, S. (2017). Economic Policy Uncertainty and Tourism Demand: Empirical Evidence from the USA. International Journal of Tourism Research, 19 (1), 99-106. https://doi.org/10.1002/jtr.2089

14. Sainaghi, R. (2012). Tourist Expenditures: The State of the Art. Anatolia - An International Journal of Tourism and Hospitality Research, 23 (2), 217-233. https://doi.org/10.1080/13032917. 2012.684217

15. Seetaram, N. (2012). Estimating Demand Elasticities for Australia's International Outbound Tourism. Tourism Economics, 18 (5), 999-1017. https://doi.org/10.5367/te.2012.0161

16. Sheldon, P.J. (1990). A Review of Tourism Expenditure Research. In C. Cooper (Eds.), Progress in Tourism, Recreation and Hospitality Management, (pp. 28-49). Belhaven Press: London.

17. United Nations World Tourism Organization (UNWTO) (2016). Tourism Highlights - 2016 Edition. The United Nations World Tourism Organization: Madrid.

18. Uysal, M., \& El Roubi, M.S. (1999). Artificial Neural Networks versus Multiple Regression in Tourism Demand Analysis. Journal of Travel Research, 38 (2), 111-118. https://doi.org/10.11 77/004728759903800203

19. Vietze, C. (2011). What's Pushing International Tourism Expenditures? Tourism Economics, 17 (2), 237-260. https://doi.org/10.5367/te.2011.0039

\section{Contact information}


Giray Gozgor, Ph.D.

Istanbul Medeniyet University

Faculty of Political Sciences

International Relations

Turkey

E-mail:giray.gozgor@medeniyet.edu.tr

Ender Demir, Ph.D.

Istanbul Medeniyet University

Faculty of Tourism

Tourism Management

Turkey

E-mail:ender.demir@medeniyet.edu.tr

\section{Appendix 1:}

The data details are as follows. Australia (1998-2015), Brazil (1995-2015), Canada (1995-2015), Chile (1995-2015), China (1995-2015), France (1995-2015), Germany (1997-2015), India (20032015), Ireland (1995-2015), Italy (1997-2015), Japan (1995-2015), the Netherlands (2004-2015), Russia (1995-2015), South Korea (1995-2015), Spain (2001-2015), the United Kingdom (UK) (1997-2015), and the U.S. (1995-2015). 